\title{
Synthetica: reflexões acerca da (i)materialidade da música em álbuns-aplicativo
}

\author{
Beatriz Brandão Polivanov
}

Lucas Waltenberg

Resumo: A partir do álbum-aplicativo Synthetica, lançado em 2013 pela banda canadense Metric, este artigo se propõe a investigar a relação entre cultura material e música na cibercultura. Em um primeiro momento, traz algumas reflexões e perspectivas sobre os conflitos entre materialidade e cultura digital. Em seguida, discute o álbum de música em um sentido mais tradicional para pensar suas aproximações e distanciamentos com o álbum-aplicativo. Por fim, analisa Synthetica, apoiado em reflexões sobre cultura remix, a materialidade da música e remediação. Conclui-se que, mesmo na cibercultura, a música possui uma complexidade material, moldando novos protocolos de escuta no diálogo entre actantes humanos e não-humanos.

Palavras-chave: materialidade; cultura digital; álbum-aplicativo; música; Synthetica.

Abstract: SYNTHETICA: Reflections on the (im)materiality of music in app-albums - Using the app-album "Synthetica", launched in 2013 by Canadian band Metric, as a study object, this paper aims to investigate the relationship between material culture and music in cyberculture. Firstly, it brings some reflections and perspectives about the conflicts between materiality and digital culture. Secondly, it discusses the music album in a more traditional sense to highlight its similarities and differences with the app-album. Lastly, it analyzes Synthetica, anchored by thoughts on remix culture, the materiality of music and remediation. We conclude that, even in cyberspace, music possesses a material complexity, shaping new "listening protocols" in the relationship between human and non-human actants.

Keywords: materiality; digital culture; app-album; music; Synthetica.

\section{Problematizando o argumento da desmaterialização da música}

Quando a música deixou de circular somente em suportes físicos para navegar pela rede mundial de computadores, os pilares sobre os quais foi construída a indústria 
fonográfica começaram a balançar. Entre olhares mais catastróficos ou mais celebratórios, são muitos os trabalhos que buscam dar conta das diversas mudanças trazidas pela produção, circulação e consumo de música na rede. Um ponto comum nas análises trata da desmaterialização da música (CASTRO, 2005; VICENTE, 2012).

Na verdade, a ideia de "desmaterialização" atravessa uma série de reflexões em torno das transformações sofridas em variados setores da indústria cultural com a popularização da internet (ROLLEMBERG, 2010; HERMANN, 2012). Aqui, devemos entender o fenômeno como a "transformação [da música] em bits" (HERSCHMANN; ALBORNOZ, 2009, p.5).

Percebemos que o argumento da desmaterialização da música é construído sobre dois pilares. O primeiro diz respeito à transmissão da música pela internet. Transformada em dados digitais, a música trafega mais facilmente pela rede mundial de computadores, via programas de compartilhamento do tipo par-a-par, sites de download, lojas virtuais ou serviços de streaming. O segundo pilar, por sua vez, trata da quebra de um suposto "rigor" dos suportes físicos, principalmente no que diz respeito à noção de álbum de música. O álbum remonta ao disco LP de $33^{1 / 3}$ rotações por minuto (rpm), posto em circulação para o público consumidor no fim dos anos 1940. Sinteticamente, o álbum é entendido como um produto fechado (SÁ, 2009, p.59), composto por imagens, textos e sons, que possibilita a artistas explorarem temas maduros e sofisticados em profundidade (KEIGHTLEY, 2001, p.116) e contribuiu para que os discos ganhassem o status de obras de arte em si (DE MARCHI, 2005, p.13).

Apoiado pela ideia de desmaterialização, o consumo de música pela internet permite aos ouvintes adquirir somente uma ou outra música específica ao invés do pacote completo, atitude que seria representativa do "fim da ditadura do álbum comercial", como pontuam Carvalho e Rios (2009).

O problema quando aceitamos o argumento da desmaterialização é que deixamos de considerar que a música possui uma série de complexidades materiais em operação mesmo nas tramas digitais da cibercultura. Como nos lembra Straw,

\section{[...] a questão da materialidade da música vem acompanhada por um conjunto de contradições e paradoxos. Por muito tempo considerada uma das formas culturais mais etéreas e abstratas, a música é indiscutivelmente aquela mais embutida nas infraestruturas materiais do nosso cotidiano (STRAW, 2012, p.227, tradução nossa).}

Portanto, mesmo observando a transformação da música em bits, precisamos considerar a utilização de reprodutores materialmente tangíveis, como celulares, computadores e tablets como instrumentos fundamentais nas práticas de produção, circulação e escuta musical. Lévy (1999, p.53) já questionava a ideia de desmaterialização na cultura digital ao perguntar: "a digitalização pode ser considerada como 'desmaterialização' da informação?". Na verdade, pondera o autor, a transformação de algo - uma foto, 
no caso - em números que serão lidos pelo computador, precisa de uma infraestrutura material onde eles serão inscritos e, posteriormente, lidos ou manipulados.

Para Sterne (2012, p.186), o problema se traduz na dúvida: "ou a música se desmaterializou ou sua materialidade existe agora em uma escala diferente". É importante apontar que nos dados digitais há, de fato, uma materialidade, ou uma micromaterialidade ${ }^{1}$. Mesmo sendo imperceptível, propomos tê-la em mente na busca de novas reflexões acerca das instâncias materiais da música na cultura digital.

Assim, perguntamos: de que maneira a música adquire uma complexidade material na cibercultura? Para dar conta dessa questão, propomos fazer um recorte acerca da ideia de álbum-aplicativo, através da análise de Synthetica, lançado pela banda canadense Metric em 2013. O objeto é sedutor, uma vez que condensa em um mesmo produto a materialidade dos dados na cultura digital enquanto propõe retomar a noção de álbum, incorporando novos protocolos de uso e escuta na relação entre banda, ouvinte e suporte.

O objetivo deste artigo é, portanto, investigar as instâncias materiais da música na cibercultura. Na primeira parte vamos nos deter no intricado diálogo entre cultura e materialidade. Em seguida, apresentamos a noção de álbum-aplicativo, apontando as aproximações e distanciamentos entre esse objeto e o álbum de música, entendido em um sentido mais tradicional. Por fim, trazemos o estudo de caso de Synthetica, contextualizando a banda, o álbum e o aplicativo e discutindo questões relacionadas à materialidade da música em meios digitais e à cultura remix.

\section{Retomando a discussão sobre a (i)materialidade da cultura}

O debate sobre a (i)materialidade da cultura teria começado a se apresentar de modo mais sistemático na década de 1970, quando surgiram os primeiros trabalhos focados em pensar as formas materiais e sua importância nas Ciências Sociais (MILLER, 1998). Não obstante, é somente a partir da década de 1980 que os estudos da materialidade e propriamente uma "teoria das materialidades da comunicação" é estruturada, no departamento de literatura comparada da universidade de Stanford (FELINTO, 2001).

Conforme defendem Sá e Polivanov (2012, p.8), duas grandes correntes teriam se configurado desde então de modo paralelo: aquela inspirada em grande medida pelos trabalhos de McLuhan "e retomada pelo círculo de Gumbrecht", deslocando "a reflexão sobre a mediação tecnológica do campo hermenêutico, político e/ou ideológico em favor da atenção à materialidade ou concretude de cada um dos canais de comunicação", e a dos estudos vinculados à antropologia, que têm principalmente nos trabalhos de Miller (1998, 2013) seu grande expoente, aventando a "possibilidade de se desenvolver uma teoria das coisas per se que não se reduza às relações sociais" (2013, p.76).

1 O termo foi usado em citação por Sterne e se refere à "contínua desmaterialização da música (ou, talvez, um termo melhor seria 'micromaterialização', uma vez que MP3s vivem em silício, tão invisíveis quanto podem ser)" (STERNE, 2012, p.194, tradução nossa). 
Quando se trata de discutir a cultura material ou as materialidades da cultura ou ainda as teorias das coisas é impossível não remeter também aos trabalhos de Bruno Latour e particularmente à teoria ator-rede (LATOUR, 2005), que critica uma postura adotada pela sociologia do social na qual o próprio social não é explicado, mas tomado como dado, em uma compreensão de mundo na qual os sujeitos têm primazia nas ações e os seres actantes não humanos são desconsiderados.

Um aspecto em comum entre tais perspectivas que merece ser destacado diz respeito a uma preocupação com a invisibilidade dos objetos até então. Daniel Miller vai afirmar que "os objetos são importantes não porque sejam evidentes e fisicamente restrinjam ou habilitem, mas justo o contrário. Muitas vezes, é precisamente porque nós não os vemos" (MILLER, 2013, p.78). E, juntamente com o fato de não serem vistos, são tidos como coisas "sem vida, resíduos físicos" de processos mais importantes e interessantes suportados por eles (STRAW, 2002, p.147) como um DVD, por exemplo, que não teria valor enquanto objeto em si (mero suporte), mas pelo conteúdo que armazena.

Desse modo, se "o imaterial só pode se expressar pelo material" (MILLER, 2013, p.111) e ainda, se entendermos a partir de Straw que a música pressupõe sempre uma materialidade, interessa-nos aqui investigar que suporte material é esse que configura o álbum-aplicativo Synthetica, lembrando que, como no caso do trabalho de Schäfer, "não se trata de analisar o conteúdo da música, mas todo o aparato que a envolve e circunda e que é responsável por ela existir" (SCHÄFER, 2013, p.97).

Cabe destacar ainda que, como ressalta Miller (2013), a ideia não é pensar as funções do objeto, buscando exatamente fugir de uma perspectiva que possa reduzir os objetos meramente à sua utilização pragmática, mas sim suas especificidades e concretudes enquanto tal, sem desconsiderar, no entanto, seus significados.

Assim, algumas questões que nortearão nossa análise vão dizer respeito a: quais são as especificidades do álbum-aplicativo quanto à sua (i)materialidade? Que os usuáriosouvintes possam mexer na obra, remixá-la, evocaria um desejo de coparticipação, de criação de construções coletivas e abertas por parte da banda? Ou ainda pode significar uma forma de nos mostrar concretamente a simbiose sinestésica - através do tato, audição e visão - entre sujeitos e objetos que se dá no processo de fruição e recriação constante da obra? O que (res)significam álbum e aplicativo nesse contexto?

Não pretendemos exaurir neste trabalho todas as questões que o objeto pode suscitar, nem ao menos pleitear respostas definitivas para as questões levantadas, mas sim trazer à tona, a partir da análise teórico-empírica, pontos relevantes para se pensar as materialidades e significados desses novos objetos, os álbuns-aplicativos, que definiremos a seguir.

\section{Álbum-aplicativo: uma tentativa de definição}

Ao falar do amadurecimento do rock e de sua legitimação, Keightley (2004) ressalta a centralidade das instituições do LP nesse processo. De 1932 a 1948 o único suporte 
amplamente disponível para o público era o disco de 78 rpm. Em 1949 a Victor-RCA passa a comercializar o single de $45 \mathrm{rpm}$.

Voltados para diferentes tipos de consumidores, ambos os formatos adotaram repertórios distintos, alinhados ao gosto de seu público. O LP, mais caro, tinha o público adulto como principal comprador. A música registrada no disco era articulada com o gosto dessa faixa etária, já legitimado culturalmente: óperas, jazz e musicais da Broadway, por exemplo. O single, por sua vez, era o suporte para a circulação da música direcionada para o público adolescente, incluindo-se aí o rock.

Assim, o mercado de álbuns representava de uma só vez uma base econômica para a indústria do disco e um lugar para a valorização de tradições ortodoxas que resistem à novidade e ao consumo "descerebrado". Esse entrelaçamento e interdependência entre valorização cultural e econômica são a chave para entender como a instituição do álbum contribuiu para a legitimação da música popular (KEIGTHLEY, 2004, p.381, tradução nossa).

O tipo de álbum que nos interessa aqui é esse que remonta ao surgimento do disco de vinil, entendendo que as histórias de ambos estão entrelaçadas (BARTMANSKI; WOODWARD, 2013). Para Straw (2012) o LP traz consigo um protocolo de escuta, que relaciona as faixas do álbum com seus paratextos, como as imagens da capa, do encarte e os textos de apresentação. Ainda que esse protocolo de escuta sugira uma relação de proximidade idealizada, quase de imersão, entre ouvinte, artista e suporte material, colecionadores costumam justificar suas preferência pelo vinil nesses termos (BARTMANSKI; WOODWARD, 2013; GAUZISKI, 2013).

Tal protocolo de escuta não ficou, no entanto, restrito ao disco de vinil. Straw (2009, p.86) aponta que os álbuns em CD também dialogavam com esse consumo ritualístico, "no qual um ouvinte se debruçaria lentamente pelo encarte que acompanha [o CD] enquanto um trabalho musical é revelado, cada um iluminando o outro dentro de uma interconexão necessária". No entanto, a materialidade do álbum em CD traz consigo um problema que não aparecia no vinil. O fato de ele ser leve e mais facilmente portátil separava a música da "embalagem, da anotação e do design intencionados a garantir o valor e a integridade do CD enquanto uma forma cultural distinta" (STRAW, 2009, p.82).

Se estendermos a discussão para o mp3, essa questão aparece com contornos mais complexos. No ambiente online, a música é mais facilmente distanciada desses paratextos que trazem uma carga simbólica para ela no conjunto do álbum. Apesar de alguns autores e críticos terem levantado a bandeira da morte do álbum, é claro que ele continua sendo uma referência importante para a cultura musical, mesmo em tempos de compartilhamento de arquivos. Artistas ainda lançam álbuns e críticos se pautam neles para articularem seus discursos. Mesmo em mp3, álbuns continuam atraentes para consumidores. 
E o disco de vinil, o primeiro referencial do álbum, vem apresentando uma espécie de retorno ${ }^{2}$, deixando de circular somente nas subculturas que o adotaram como representativos de suas práticas. Ou seja, mesmo com o desenvolvimento de novos suportes de reprodução musical, o álbum permanece um formato cultural para trabalhos musicais serem apresentados de forma mais aprofundada, conectando canções a imagens, textos e embalagem, na tentativa de criar uma unidade sonora e estética.

Com a popularização de tablets e smartphones, artistas vêm explorando a possibilidade de distribuir suas músicas em aplicativos, tornando-os um canal de interação constante com os fãs (BUSKIRK, 2009). No entanto, a ideia de criar um aplicativo para um álbum específico tomou forma apenas em 2011, quando a islandesa Björk lançou Biophilia. O aplicativo, criado inicialmente para iPad, iPhone e iPod Touch, foi desenvolvido em parceria com o Snibbe Studio e traz não somente as músicas do álbum - que, por sinal, foi composto parcialmente em um iPad - mas também animações, textos, imagens interativas e jogos. Cada mini-aplicativo dentro do aplicativo principal representa uma música do álbum e traz os seus próprios meios de navegação, relacionados ao tema explorado na canção.

Scott Snibbe, principal desenvolvedor do aplicativo Biophilia e do álbum-app REWORK_, parceria entre Beck e Philip Glass, insiste que um dos valores dos álbuns-app está na ideia de imersão, que remonta ao LP:

[...] o conceito de imersão na música (...) acontecia quando pegávamos um disco de vinil e o escutávamos, olhando o encarte e lendo as letras, completamente esquecidos do mundo enquanto nos apaixonávamos pela música. (...) Os formatos digitais nos tiraram um pouco dessa capacidade. Graças a eles, ouvimos música em movimento, enquanto escovamos os dentes (...) é como se mantivéssemos um relacionamento amoroso superficial com a música. "Biophilia" é uma experiência (...) de nos fazer parar e ouvir a música com profunda atenção. A diferença é que agora o encarte, as fotos, as imagens, tudo está em movimento (SNIBBE apud ALBUQUERQUE, 2011, online, tradução nossa).

O que chama a atenção nos álbuns-apps é a sua dinâmica quase ambígua de distanciamento e aproximação com os suportes musicais que vieram antes deles. Os aplicativos não são estáticos como o disco de vinil ou o CD; ao contrário, eles oferecem visualizações interativas, animações, jogos e pop-ups como uma forma de complementar a música que sai do alto-falante do dispositivo móvel. Ao mesmo tempo, ele se inspira na conexão entre o álbum e as cargas simbólicas invocadas pelas imagens e textos que complementam e trazem sentido para as músicas, configurando uma obra que se pretende coerente e interconectada.

Além do mais, como aparece na fala de Snibbe, a imersão pressuposta pela audição de álbuns em aplicativo está diretamente relacionada com o protocolo de escuta do disco

2 Bartmanski e Woodward (2013, p. 1) chegam a afirmar que "álbuns de vinil são atualmente a área que cresce mais rápido em venda de música". 
de vinil ou do CD. A diferença é que, no aplicativo, a imersão pressupõe uma participação mais intensa do ouvinte. Não basta virar o disco ou apertar o play; é preciso tocar, arrastar, ir, voltar, assistir, remixar e jogar para que a experiência seja completa.

Posto isso, entendemos álbum-aplicativo como o software desenvolvido para dispositivos móveis, que traz um álbum específico envolto em elementos complementares às músicas, invocando um protocolo de escuta direcionado pelos recursos interativos utilizados pelos desenvolvedores do app. Em seguida, vamos explorar melhor essa definição com a análise do aplicativo Synthetica da banda Metric.

Antes, porém, ressaltamos que estamos usando a noção de protocolo de escuta e remediação como recursos metodológicos para abordar o objeto, bem como uma tentativa de traçar uma inicial cartografia de controvérsias ${ }^{3}$ em relação a ele. Essas ideias vão operacionalizar a análise interpretativo-empírica, pois nos permitem olhar criticamente não somente para a materialidade do suporte onde a música é registrada, como também os construtos socioculturais fomentados pelo álbum de música enquanto um formato culturalmente significativo.

Compreendemos também que a complexidade do álbum-app, a carência de trabalhos que pensam essa categoria de suporte fonográfico e, ainda, principalmente, a ideia defendida por Lemos de que, para a Teoria Ator-Rede4, "um trabalho não é bom se não for descritivo o bastante" (2013, p.91), nos obrigam a adotar uma postura que, em um primeiro momento, pode parecer excessivamente descritiva.

Nosso objetivo é oferecer ao leitor uma cartografia inicial das controvérsias trazidas por Synthetica na qual diferentes fontes foram utilizadas para a coleta de informações, como o próprio álbum-app, críticas musicais, entrevistas e o material voltado para a imprensa, publicado no site oficial da banda na internet. Procuramos, assim, nos afastar de uma descrição meramente superficial para mostrar como o objeto - que a nosso ver está longe de se conformar como caixa-preta, com actantes ainda não harmonizados, mas em plena circulação inacabada (LEMOS, 2013, p.111) - permite articular questões sobre a materialidade da música e dos protocolos de escuta do álbum no universo das novas tecnologias.

\section{Análise de Synthetica}

Metric é uma banda canadense, fundada no final dos anos 1990, cuja proposta sonora circula entre os chamados indie rock e o synthpop. Mesmo sem o suporte de uma grande gravadora, o grupo vem crescendo no decorrer dos anos, contando com parcerias

3 "A CC [cartografia de controvérsias] é um conjunto de técnicas para explorar e visualizar polêmicas, questões emergentes em determinados agrupamentos, o movimento, a circulação da ação e a fluidez das mediações, revelando as diversas dimensões que compõem uma rede sociotécnica", não requerendo para tal "um método ou uma teoria específicos" (LEMOS, 2013, p. 110-111).

4 Que inspira em parte o presente artigo. 
internacionais para alargar a esfera de circulação de seu trabalho. Synthetica é o quinto álbum de estúdio do Metric. Para a vocalista Emily Haines o álbum é "sobre ser capaz de identificar o original em uma longa fila de reproduções. É sobre o que é real vs o que é artificial" (HAINES, 2012, online).

Conforme James Shaw, guitarrista e produtor do Metric, a banda não deu início à gravação do álbum com um conceito bem definido, "foi somente durante o processo que começamos a nos dar conta que o tipo de tema (...) era realmente sobre a duplicidade de todo o tipo de coisa e a dicotomia entre um lado e outro de todas as coisas diferentes na vida" (SHAW, 2012, online).

Conforme críticas publicadas em sites especializados e nos releases divulgados pela banda, parte do conceito de Synthetica foi inspirado por imagens criadas pelo coletivo de arquitetura italiano Superstudio, em atividade nos anos 1960 e $1970^{5}$. Algumas dessas imagens também foram usadas no próprio app. Ainda sobre o desdobramento imagético de Synthetica, o fotógrafo e designer Justin Broadbent, que criou a imagem da capa (FIG. 1), reflete enigmaticamente que gosta de "olhar para coisas que estão olhando para coisas. Eu tentei criar uma linda paisagem que não se ajusta confortavelmente com o espectador", afirmando que há ali "uma perfeição sintética nas cortinas douradas. Como batom fresco, é precioso, mas temporário. Tudo o mais é um espelho" (BROADBENT, 2012, online).

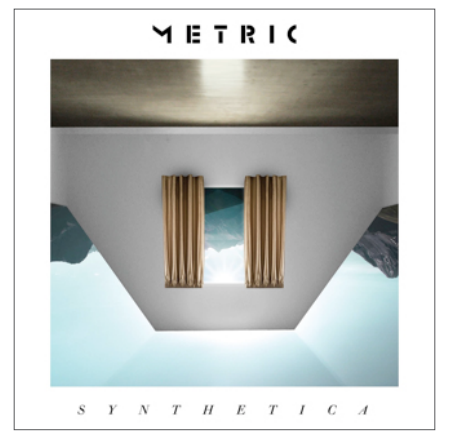

Fig. 1.Capa do álbum Synthetica. Fonte: Press Release ${ }^{6}$.

Em 12 de novembro de 2013 o Metric lançou pela iTunes Store um álbum complementar (companion album) ao Synthetica, denominado Synthetica Reflections. De acordo com o release publicado no site oficial da banda ${ }^{7}$, esse segundo produto é uma releitura instrumental do álbum original, cujas músicas foram recriadas com vários sintetizadores. No mesmo dia, a banda também começou a comercializar pela loja de aplicativos da Apple, a App Store, o app do álbum Synthetica, sob o nome Metric. O álbum-aplicativo contém onze song experiences, como são chamados os mini-aplicativos dentro do aplicativo principal.

5 Mais informações disponíveis em: <http://en.wikipedia.org/wiki/Superstudio>. Acesso em: 12 fev. 2014.

6 Disponível em: <http://www.ilovemetric.com/press/>. Acesso em: 12 fev. 2014

7 Disponível em: <http://ilovemetric.com/press/>. Acesso em: 12 fev. 2014. 
O álbum-aplicativo, que pode ser baixado gratuitamente pela loja virtual, já vem com a song experience Lost Kitten ${ }^{8}$ e foi desenvolvido pelo Snibbe Studios, o mesmo produtor do álbum Biophilia e o de REWORK_. Sobre o lançamento do app, Emily Haines, vocalista do Metric, explica que

[...] é como uma versão atualizada de quando você pega um vinil e o abre. Você ouve este disco enquanto olha para as figuras e se perde na imagem. Eu sinto como se o que eles tivessem criado conosco é uma versão atualizada dessa experiência (HAINES, 2013, online).

O álbum-aplicativo do Metric é um convite ao remix, entendido aqui como uma abertura à apropriação dos conteúdos criados pela banda de modo a se criar algo novo (LESSIG, 2008, p.52). No app, o usuário pode manipular as canções ou os trechos de música, seja recriando sequências de samples ou aplicando filtros sonoros. Em seis dos aplicativos, a experiência de remix é atingida na manipulação dos sequenciadores em 3D que se misturam às imagens (FIG. 2). O usuário pode escolher o instrumento, a velocidade e os samples que serão usados na sequência, criando pequenos trechos com elementos das canções. Nos cinco restantes, o usuário interfere diretamente na música através de filtros como pitch e reverb ${ }^{9}$, arrastando o dedo na tela (FIG. 3).

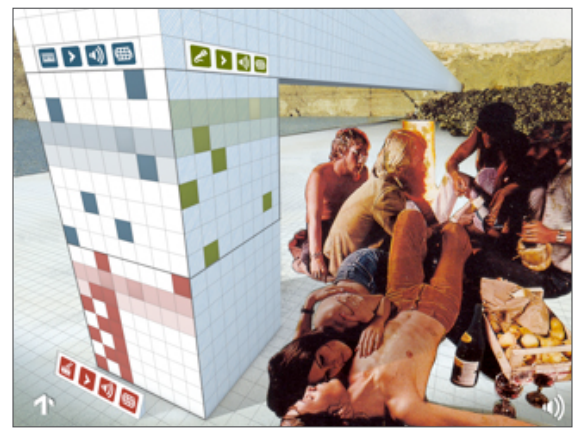

Fig. 2. Song experience de Youth without youth. Fonte: Press release $\mathrm{i}^{10}$

8 Cada uma das song experiences pode ser adquirida individualmente por US\$ 0,99. O usuário também pode comprar o pacote completo por US\$7,99, que vem com as dez músicas adicionais. Do total dos onze aplicativos "internos", nove correspondem a canções do álbum Synthetica; os dois restantes trazem as músicas Reflections 5 e Reflections 6, de Synthetica Reflections.

9 O pitch está relacionado à alteração de semitons de um evento sonoro, tanto para mais grave quanto para mais agudo. Reverb é um efeito que se aplica para simular a reverberação sonora da espacialidade de diferentes ambientes.

10 Disponível em: <http://www.ilovemetric.com/press/>. Acesso em: 12 fev. 2014. 


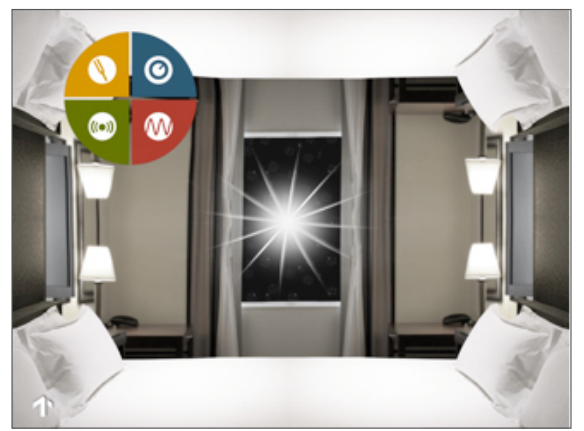

Fig. 3. Song experience de Artificial nocturne. Fonte: Press release ${ }^{11}$

Toda a lógica de interação permitida e pressuposta pelo aplicativo nos faz refletir sobre um novo modo de fruição do álbum musical, que impede que concebamos seus consumidores como meros ouvintes e seu suporte - o próprio aplicativo em um smartphone ou tablet - como mero dispositivo tocador de música. O ouvinte torna-se também compositor e o dispositivo tocador passa a agir também como instrumento musical na medida em que permite a (re)criação de sons ${ }^{12}$.

Fazemos, no entanto, uma importante ressalva: no álbum-app já estão préprogramados os sons que podem ser alterados e criados no software, havendo, portanto, limites pré-estabelecidos pelos actantes humanos (a banda e os desenvolvedores do aplicativo) e não humanos (o software, o smartphone, o tablet) no campo de possibilidades de atuação no álbum.

Traçando um paralelo com os aparelhos que produzem imagens técnicas, dos quais fala Flusser (1985), e indo além das câmeras fotográficas, trata-se, no caso do aplicativo, de uma máquina já programada para produzir certas imagens - reconhecendo as imagens não apenas como aquilo que é da ordem do visual, mas também do som - de formas específicas. Nas palavras de Machado, "isso quer dizer que uma máquina semiótica condensa em suas formas materiais e imateriais um certo número de potencialidades e cada imagem técnica produzida através dela representa a realização de algumas dessas possibilidades" (1997, s/p).

Buscamos chamar a atenção, assim, para a complexidade do objeto álbum-aplicativo que diz respeito também à invisibilidade e intangibilidade dos actantes que compõem seu sistema (elementos que compõem o software e as próprias músicas), conforme discutido

11 Disponível em: <http://www.ilovemetric.com/press/>. Acesso em: 12 fev. 2014.

12 Ressalta-se, no entanto, 1) que não corroboramos a leitura de que a ação de ouvir seja mais passiva do que a de tocar ou produzir música, bem como entendemos que os atores sociais nunca são apenas receptores nem emissores das mensagens, mas sim coconstrutores das mesmas. E 2) mesmo em dispositivos mais antigos que não pressupõem a intervenção dos atores no som reproduzido, tal intervenção é passível de ocorrer, como quando, por exemplo, é feito scratch em vinis. Ou seja, a diferença - ainda que significativa - entre os dispositivos recairia em uma predisposição maior ou menor para os conteúdos serem remixados. 
acima, evocando uma sensação de não mediação entre o actante humano e a música, que pode ser tocada, palavra aqui propositalmente ambígua, referindo-se tanto ao toque físico no smartphone ou tablet quanto ao sentido de colocar uma música para ser tocada. Perguntamos, então: como o formato álbum-app atualiza o protocolo de escuta do álbum na mediação entre ouvintes e músicas?

Ao pensar sobre remediação, Bolter e Grusin (2000) falam da dupla lógica que a norteia: a imediação e a hipermediação. A imediação diz respeito a uma transparência do meio, onde o espectador teria a impressão de ficar em contato com aquilo que é representado, desenvolvendo uma relação mais íntima e imersiva. Por outro lado, a hipermediação aponta para um estilo de representação que preza pela fragmentação e pela heterogeneidade. A navegação online seria um exemplo de hipermediação, uma vez que, combina imagens, vídeos, sons e textos em um mesmo espaço.

Assim, "se a lógica da imediação leva-se a ou apagar ou a tornar automático o ato da representação, a lógica da hipermediação reconhece múltiplos atos de representação e os torna visíveis" (BOLTER; GRUSIN, 2000, p.33-34). A remediação, entendida pelos autores como a "representação de um meio em outro" (p.45), operaria segundo essas duas lógicas.

Ainda que Bolter e Grusin tenham elaborado o conceito no final dos anos 1990, propomos retomá-lo para pensar a relação entre o formato álbum, entendido em termos mais tradicionais, e o álbum-aplicativo. Como um álbum, o app de Synthetica traz as músicas e o trabalho gráfico correspondente ao tema explorado, criando um repertório sonoro e imagético em torno de um produto musical. Entretanto, o protocolo de escuta aqui é expandido em outras direções. Não basta somente ver as imagens, ler os textos e ouvir as músicas, como se fossem três instâncias mais ou menos separadas. A experiência só se torna completa na manipulação do software através de toques na tela, os quais modificam a música e a imagem à medida que os sons saem do alto-falante acoplado ao dispositivo.

Nesse contexto, ouvir Synthetica é usar Synthetica. Trata-se, portanto, de um ato de remediação que conjuga a lógica dupla da imediação e da hipermediação, uma vez que o sujeito, através de toques na tela, coloca-se em contato mais direto com a música, intervindo diretamente nela, como se o meio fosse apagado. Ao mesmo tempo, o usuário lida com um complexo hipermidiático que traz animações, imagens, sons, botões, menus e controles, exercendo todos esses actantes - humanos e não humanos - papéis igualmente importantes na fruição do objeto.

\section{Considerações finais}

Buscamos neste trabalho discutir, com base em um estudo de caso do aplicativoálbum Synthetica da banda Metric, aspectos relacionados às teorias das materialidades que pudessem nos ajudar a pensar sobre, por um lado, uma suposta desmaterialização da música na cultura digital e, por outro, a proposta de uma nova categoria de dispositivo musical que reconfigura a noção de álbum. 
Práticas culturais e novas tecnologias desenvolvidas no âmbito da cibercultura vêm ressignificando uma série de entendimentos em relação aos bens culturais que circulam pela internet. Apesar do argumento da desmaterialização da música destacar o seu descolamento dos suportes físicos mais tradicionais, optamos por tomar um caminho menos explorado para mostrar como a música adquire novas complexidades materiais nesse contexto. Os dispositivos móveis possuem uma existência material mais óbvia. No entanto, os aplicativos que tocam as músicas também possuem uma tangenciabilidade que não pode ser desconsiderada.

Através da análise do objeto e da revisão bibliográfica empreendida, defendemos que ele evoca uma lógica ambígua: ao mesmo tempo em que pressupõe e torna claro o entrelaçamento entre actantes humanos e não humanos, entre pessoa e aplicativo (e o dispositivo no qual está aquele aplicativo, um smartphone ou um tablet) na recomposição das faixas do álbum, reforçando a materialidade e existência dessa relação através do toque, da visão e da audição - algo menos claramente perceptível quando, por exemplo, baixamos uma música de um computador e a ouvimos ali - ele também tende a apagar tal entrelaçamento, uma vez que se tratam de dados digitais, intangíveis e micromaterializados inseridos em uma caixa preta cujo funcionamento deve permanecer obscuro frente à sua função lúdica, imersiva e estética.

O álbum-aplicativo traz, assim, um novo protocolo de escuta, que convoca o actante humano para interferir em seu conteúdo através do toque, para ouvir as faixas musicais na ordem em que bem entender, para tornar os vocais mais ou menos agudos, para acrescentar ou tirar instrumentos, ao mesmo tempo em que apresenta um repertório imagético visual, em uma experiência sinestésica e multissensorial. Synthetica nos conclama assim, a mexer com o olhar, o ouvir e o sentir as coisas que estão olhando para coisas.

Beatriz Brandão Polivanov é pesquisadora de pós-doutorado pelo Programa de Pós-Graduação em Comunicação da Universidade Federal Fluminense com bolsa Capes.

beatriz.polivanov@gmail.com

Lucas Waltenberg é doutorando pelo Programa de Pós-Graduação em Comunicação da Universidade Federal Fluminense com bolsa Capes.

Iwaltenberg@gmail.com 


\section{Referências}

ALBUQUERQUE, C. Parceiro de Björk em "Biophilia" diz que aplicativos nos farão voltar a ouvir música com atenção. Jornal O Globo, nov. 2011. Disponível em: <http://oglobo.globo. $\mathrm{com} /$ cultura/parceiro-de-bjork-em-biophilia-diz-que-aplicativos-nos-farao-voltar-ouvir-musica-comatencao-3215442>. Acesso em: 4 fevereiro de 2014.

BARTMANSKI, D.; WOORDWARD, I. The vinyl: the analogue medium in the age of digital reproduction. Journal of Consumer Culture, 2013. Disponível em: <http://joc.sagepub.com/content/ early/2013/05/30/1469540513488403.abstract>. Acesso em: 8 de março de 2014.

BOLTER, J.; GRUSIN, R. Remediation: understanding new media. Cambridge: MIT Press, 2000.

BUSKIRK, E. "The album is dead, long live the app". Wired, abr. 2009. Disponível em: <http://www. wired.com/business/2009/08/the-album-is-dead-long-live-the-app/>. Acesso em: 4 fev. 2014

CARVALHO, A.; RIOS, R. O mp3 e o fim da ditadura do álbum comercial. In: PERPETUO, I.; SILVEIRA, S. (orgs.). O futuro da música depois da morte do CD. São Paulo: Momento Editorial, 2009.

CASTRO, G. Para pensar o consumo da música digital. FAMECOS, Porto Alegre, n. 28, p.30-36, 2005.

DE MARCHI, L. A angústia do formato: uma história dos formatos fonográficos. E-Compós, Brasília, v. 2, 2005. Disponível em: <http://compos.org.br/seer/index.php/e-compos/article/viewFile/29/30>. Acesso em: 8 de março de 2014.

FELINTO, E. Materialidades da comunicação - por um novo lugar da matéria na teoria da comunicação. Ciberlegenda, Niterói, n. 5, 2001.

FLUSSER, V. Filosofia da caixa preta. São Paulo: Hucitec, 1985.

GAUZISKI, D. O resgate do vinil: uma análise do mercado atual e dos colecionadores na cidade do Rio de Janeiro. Ciberlegenda, Niterói, n. 28, p. 83-94, 2013.

HERMANN, L. A convergência midiática e as mudanças comportamentais no consumo do mercado de nicho: Netflix e a "desmaterialização" dos produtos. Animus, Santa Maria, v. 11, n. 22, p. 222245, 2012.

HERSCHMANN, M.; ALBORNOZ, L. Transformações recentes na indústria da músic. In: ENECULT, 5, Salvador. Anais...Salvador, 2009.

KEIGHTLEY, K. Reconsidering rock. In: FRITH, S.; STRAW, W.; STREET, John (orgs.) Cambridge companion to pop and rock. New York: Cambridge University Press, 2001.

. Long play: adult-oriented popular music and the temporal logics of the post-war sound recording industry in the USA. Media, culture \& society, v. 26, n. 3, 2004. Disponível em: <http:// mcs.sagepub.com/content/26/3/375.full.pdf>. Acesso em: 8 de março de 2014 .

LATOUR, B. Reassembling the social - An introduction to actor-network-theory. Oxford: Oxford University Press, 2005.

LEMOS, A. A comunicação das coisas - Teoria ator-rede e cibercultura. São Paulo: Annablume, 2013.

LESSIG, L. Remix: making art and commerce thrive in the hybrid economy. London: Bloomsbury Academic, 2008.

LÉVY, P. Cibercultura. São Paulo: Ed. 34, 1999.

MACHADO, A. Repensando Flusser e as imagens técnicas. In: Arte en la Era Electrónica - Perspectivas de una nueva estética, Barcelona. Anais... Barcelona, 1997. 
MILLER, D (org.). Material cultures - Why some things matter. London: UCL Press Limited, 1998. Zahar, 2013.

Trecos, troços e coisas - Estudos antropológicos sobre a cultura material. Rio de Janeiro:

ROLLEMBERG, M. O futuro do livro ou a crise na cibercultura. Revista USP, São Paulo, n. 87, p. 225-230, 2010.

SÁ, S. O CD morreu? Viva o vinil!. In: PERPETUO, I.; SILVEIRA, S. (orgs.). O futuro da música depois da morte do CD. São Paulo: Momento Editorial, 2009.

; POLIVANOV, B. Materialidades da comunicação e presentificação do sujeito em sites de redes sociais. In: Encontro Anual da Compós, 21, Juiz de Fora. Anais... Juiz de Fora, 2012.

SCHÄFER, C. Chipmusic e a teoria das materialidades: como o aparato tecnológico configura a produção musical no coletivo Chippanze. Revista Novos Olhares, São Paulo, v. 2, n. 1, p. 94-100, 2013.

STERNE, J. MP3: The meaning of a format. Durham and London: Duke University Press, 2012.

STRAW, W. Music as commodity and material culture. Repercussions, v. 7-8, 2002. Disponível em: $<$ http://www.academia.edu/4643896/Music_as_Commodity_and_Material_Culture >. Acesso em: 4 de fevereiro de 2014.

. The music CD and its ends. Design and Culture, v. 1, n. 1, 2009. Disponível em: <http:// strawresearch.mcgill.ca/CDanditsends.pdf>. Acesso em: 4 de fevereiro de 2014.

. Music and material culture. In: CLAYTON, M.; HERBERT, T.; MIDDLETON, R. (orgs.). The cultural study of music: a critical introduction. London and New York: Routledge, 2012.

VICENTE, E. Indústria da música ou indústria do disco? A questão dos suportes e de sua desmaterialização no meio musical. Rumores, São Paulo, ed. 12, ano 6, n. 2, p. 194-213, 2012. 